\title{
Online Purchase Intention Based on TAM and IAM: A Literature Review
}

\author{
Yu Wang* \\ Department of Economic and Management, Tohoku University, 2 Chome-1-1 Katahira, Aoba Ward, Sendai \\ City, Miyagi Prefecture, Japan. \\ * Corresponding author. Tel.: +86-13631533442; email: whc631211@vip.163.com \\ Manuscript submitted April 12, 2017; accepted June 5, 2017. \\ doi: 10.17706/ijeeee.2018.8.2.66-73
}

\begin{abstract}
With the popularity of Internet and the appearance of e-commerce, the issue about how to affect the purchase intentions of Internet users becomes one of the most popular topics in the research field of consumer behavior. Obviously, understanding the relevant mechanism contributes greatly to utilizing the influential factors to affect consumers. Among relevant researches, the researches based on the Technology Acceptance Model (TAM) and Information Adoption Model (IAM) are representative, valuable and practical. Hence, this article analyzes and summarizes the existing studies using TAM and IAM for studying online purchase intention respectively by dividing those studies into different categories: 1) using original model, 2) adding variables into the model and 3) building up complex models based on the model. Finally, implications are provided for future research and applications.
\end{abstract}

Key words: Technology acceptance model (TAM), information adoption model (IAM), purchase intention.

\section{Introduction}

Internet now develops at an unprecedented speed and thus becomes an indispensable part of individuals' life. With information technology permeating many facets of individuals' work and life, the use of information technology in the form of electronic commerce expands greatly. For example, individuals are now able to use various websites to share and search for information and to purchase products or service online. Hence, the question about how to affect the purchase intentions of Internet users becomes one of the hottest topics in the related research field. Additionally, it is crucial for companies to understand and utilize the influential factors to affect the intentions of potential consumers to purchase online.

Previous researches show that consumer behavior is analyzed from different perspectives and explained by different models.

Among the models and theories, Technology Acceptance Model (TAM) [1] and Information Adoption Model (IAM) [2] are comparatively representative and practical and in particular, can be used to investigate the purchase intentions of Internet users. On one hand, TAM is used to explain and predict the determinants of individuals' acceptance of information technology [1] and it continues to be the most widely used model in the Information System field [3]. Researchers have extended and tested TAM with different variables in various applications and thus have increased its explanatory power in many contexts, including banking technology, email, online games, desktop video conferencing and so forth [4]. Particularly, since online consumers exhibit the features of being both traditional consumers and information systems users, some researchers use TAM to study their purchase intentions. On the other hand, IAM is used to explain how 
individuals are affected by the online information [2]. Since the online information plays an important role in consumers' purchase decision making process [5], [6], IAM can be used to study the purchase intentions.

Obviously, researchers use TAM to analyze the influential factors of the purchase intentions of Internet users from the perspective of their Internet technology acceptance process, while IAM is used to analyze them from the perspective of their information adoption process. These two models actually represent different perspectives to study the same issue if they were used to study the purchase intentions of Internet users, are complement to each other and contribute greatly to researchers' understandings of online purchase intentions of Internet users.

Consequently, academic database, such as Elesevier, SpringerLink, Sciencedirect and others, and search engines, such as Google, are used to collect relevant literature about the applications of both TAM and IAM on studying the influential factors of online purchase intentions respectively. Then this article categorized them into three types, and illustrates future research directions to help researchers to have a better understanding of the relevant applications of both TAM and IAM in the emerging e-commerce market.

\section{TAM}

\subsection{Introduction of TAM}

Technology Acceptance Model (TAM) was illustrated by [1]. It is to "provide an explanation of the determinants of computer acceptance that is general, capable of explaining user behavior across a broad range of end-user computing technologies and user populations, while at the same time being both parsimonious and theoretically justified" [1].

According to [1], perceived usefulness is defined as "the prospective user's subjective probability that using a specific application system will increase his or her job performance within an organizational context", while perceived ease of use refers to "the degree to which the prospective user expects the target system to be free of effort." These two variables, both being affected by external variables, have crucial influences on the users' attitudes towards using the computer system and finally impact their actual use behavior, and that perceived ease of use affects the perceived usefulness, but not vice versa [1].

Hence, TAM can be used to explain the determinants of user acceptance of information systems and technology by measuring individuals' intentions, and to explain their intentions by measuring their attitudes, subjective norms, perceived usefulness, perceived ease of use, and external variables (See Fig. 1).

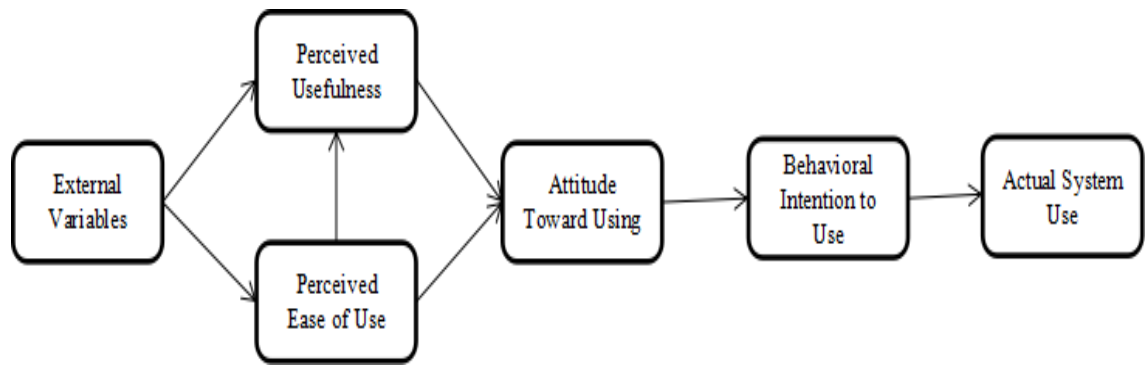

Fig. 1. TAM.

\subsection{Applications of TAM}

Although TAM was developed to explain user acceptance of technology in the workplace at the beginning, its applications have convinced researchers of its applicability in other technological adoption situations with appropriate adjustments [7], [8].

Particularly, TAM can be used to analyze the purchase intentions of Internet users and its applications 
have great theoretical and practical significance. It is mainly because that Internet users have dual characteristics of being both traditional consumers and information systems users [9].

Consequently, previous researches have shown some applications of TAM on purchase intention of Internet users and these studies can be divided into three categories, including researches on

1) using the original TAM [10].

2) adding variables to TAM [9], [10], [12]-[18].

3) building up complex models based on TAM [4], [19]-[25].

\section{IAM}

\subsection{Introduction of IAM}

Information Adoption Model (IAM) was pointed out by [2] and it can explain how individuals adopt information to change their intentions and behaviors within the computer-mediated communication platforms.

IAM is evolved from both TAM and dual process model of informational influence (e.g. Elaboration Likelihood Model). On one hand, according to TAM, people form intentions to adopt a technology or behavior based on their perceptions of the consequences. From the information adoption-based view, the process of people forming intentions to adopt ideas is similar to the process of adopting a technology and behavior. Hence, TAM is useful for explaining how intentions toward a message are formed. On the other hand, the questions about the influence process can hardly be explained by TAM and thus it is essential to use ELM to explain the process by which individuals will be influenced by the messages that they receive [26]. According to ELM, informational influence occurs at any degree of receiver elaboration, and two different influence routes, which include a central one and a peripheral one, affect the results. If the individual carefully think about the information, a high level elaboration is obtained and the information influences occur in the central route. Contrarily, if the individual has only a little consideration on the information, a low level elaboration is obtained and the information influence occurs in the peripheral route.

Therefore, TAM and ELM were integrated to build a new model, and used the argument quality as the central route, the source quality as the peripheral route, the perceived information usefulness as a mediator (See Fig. 2) [2].

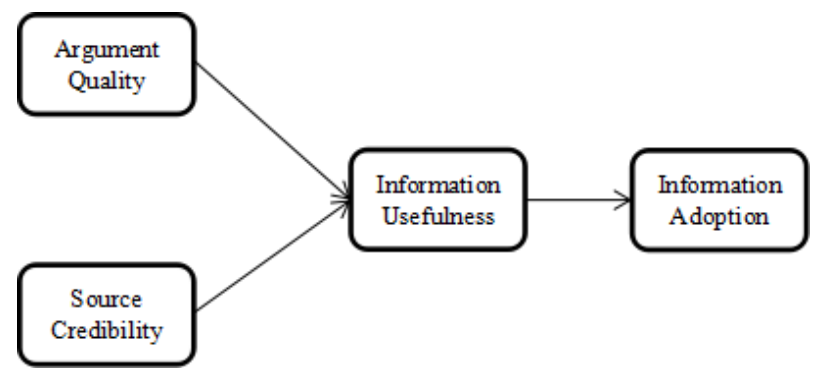

Fig. 2. IAM.

\subsection{Applications of IAM}

IAM is widely used in the studies about consumers' information adoption process of the information from the website [27], online community [28], social network [29] and electronic word-of-mouth [28], [30]. In particular, it is used for studying the online purchase intention and the relevant studies can be divided into two categories, including researches on 
1) adding variables to IAM [31];

2) building up complex models based on IAM [32], [33].

\section{Discussion and Future Research Directions}

According to the analysis above, several implications for future researches are concluded as following.

1) Future researchers could introduce new variables or other models to improve the explanatory power of TAM and IAM.

On one hand, previous researches show that in order to study the purchase intentions of Internet users, some researchers used the original TAM and some of them added variables to TAM. Furthermore, some of them built up complex models based on TAM. Obviously, out of different emphases, these researchers make these various applications of TAM (See Table 1).

Table 1. Listed in Chronological Order

\begin{tabular}{|c|c|}
\hline Researchers & Emphases \\
\hline$[10]$ & TAM \\
\hline$[19]$ & TAM+ compatibility, privacy, security, attitude, normative beliefs and self-efficacy \\
\hline$[11]$ & TAM+ trust \\
\hline$[9]$ & TAM+ perceived convenience, perceived safety \\
\hline$[12]$ & TAM+ trust+ perceived risk \\
\hline$[13]$ & TAM+ trust \\
\hline$[21]$ & TAM+ cognitive absorption+ fashion involvement \\
\hline$[14]$ & TAM+ perceived reliability, perceived product/system/service quality \\
\hline$[20]$ & TAM+ compatibility+ website quality+ perceived risk+ trust \\
\hline$[15]$ & TAM+ IDT+ perceived risk \\
\hline$[16]$ & TAM+ TRA+ perceived risk+ perceived entertaining+ subjective norms \\
\hline$[17]$ & TAM+ TPB+ TRA+ perceived risk \\
\hline$[4]$ & TAM+ trust+ enjoyment \\
\hline$[22]$ & TAM+ trust+ credibility+ risk +four demographic variables \\
\hline$[23]$ & TAM+ information/service/system quality+ perceived enjoyment \\
\hline$[18]$ & TAM+ perceived risk+ sales promotion \\
\hline$[24]$ & TAM+ subjective norm \\
\hline$[25]$ &
\end{tabular}

According to literature review, it is clear that 1) trust, 2) perceived risk and 3) other personal perceptions are three main emphases of researchers when they use TAM to study the online purchase intention. Since the researchers are aiming at study the individuals' intentions in the e-commerce settings, these three emphases are crucial.

Firstly, because the outlook for e-commerce depends both on the technology acceptance of Internet users as transaction means and on their recognition of the Internet as a reliable environment [22] and because trust could mitigate the feelings of uncertainty when something is unknown in the shopping process [34], the influence of trust can hardly be neglected and thus many researchers tested and confirmed its influence when they study the consumer' online purchase intention [4], [11]-[13], [20], [22].

Secondly, because perceived risk, defined as the risk of the consumers' perceptions of the uncertainty and adverse consequences when they are going to purchase a product or service online [35], inhibits Internet users' purchase intention, many researchers added perceived risk into their models and confirmed its negative influence on the purchase intentions [12]-[17], [20], [22]. 
Thirdly, because consumer perception of price, quality, value and other affect consumers' shopping behavior [36], many researchers investigate the influence of personal perceptions, including perceived convenience and perceived safety [9], perceived reliability [14], [22], perceived product/system/service quality [14], [23], perceived entertaining [16], [23], and confirmed their positive influences on the purchase intention on the potential consumers online.

On the other hand, previous researches show that some researchers added new variables designed according to the e-commerce environment to the original IAM [31] and that some researchers built up complex models based on IAM [32], [33], (See Table 2) Although the issue of using IAM to study the online purchase intention is still in the early stages of investigation, inside the existing researches, the trust and perceived risk were also taken into consideration.

Table 2. Listed in Chronological Order

\begin{tabular}{|c|c|}
\hline Researchers & Emphases \\
\hline$[32]$ & IAM+ trust \\
\hline$[31]$ & IAM+ needs of information \\
\hline$[33]$ & IAM+ perceived risk \\
\hline
\end{tabular}

Obviously, when extending TAM or IAM to study the purchase intentions of Internet users, researchers need to consider the new influential factors which can be related to the individual themselves, such as their perceptions, and which also can result from the rapidly developing technology and environment so as to improve the explanatory power of the model. For example, the differences in the online shopping environment may lead to different degrees of perceptions of these Internet users. For another example, social influence plays an important role in human behavior and decision making [3], [37] and thus can hardly be neglected. Furthermore, the Internet enables users to communicate and interact online and thus the influence from other users, such as tie strength, also need to be taken into consideration. Tie strength is an important antecedent of purchase intention and decision [5], [38] and prior studies show that Individuals with strong ties always have greater trust to other others and share more feelings and opinions; meanwhile their information is considered to be more credible, when compared with that from individuals with weak ties [39]-[42]. Although the issue of social influence is still in the early stages of investigation, researchers can find more linkage between social influences and purchase intention in the future.

Consequently, in order to increase the explanatory power of the model, future researches could add more variables or combine TAM/IAM with other models.

2) Future researchers could adopt more methods to collect data

Some researchers chose the convenient sampling, which actually to some degree impedes the generalization of findings to the entire city or the country. The sample from a highly homogenous group in an area may lack the diversity which can be obtained from a sample from across an entire country or the world. Hence, it is essential for further research to use a larger sample that can mirror the characteristics of online potential consumers more closely to ensure the generalizability of the models.

On the other hand, most studies above used questionnaires to collect data. However, this method may be limited by many factors, such as time and place, and thus may lead to the sample data' failing to reflect the real situation. Consequently, future researches could adopt more methods to collect data, such as using open and valuable data which has been collected by some professional websites or companies.

3) Future researchers could use a longitudinal survey to obtain more accurate data.

All the researches introduced above chose to have cross-sectional studies and thus the answers from the respondents, in great possibility, only represent their opinions when they are answering the questionnaire and fail to track their changes in the long time. The perceptions and intentions of users could change over 
time and it is crucial to measure these variables at several points of time [3]. Hence, it is necessary to use longitudinal studies to track the respondents, to figure out their changes more clearly and to grasp the influential factors which affect their intentions more accurately.

4) Future researches could focus more on the applications of the studies in different countries

Due to the different situations in different counties, future researches could explore more variables which fit to other counties' situations to improve the generalizability of the research model and to give more valuable and practical conclusions and implications.

\section{References}

[1] Davis, F. D. (1986). A Technology Acceptance Model for Empirically Testing New End-User Information Systems: Theory \& Results. Doctoral dissertation, Sloan School of Management, Massachusetts Institute of Technology.

[2] Sussman, S. W., \& Siegel, W. S. (2003). Informational influence in organizations: An integrated approach to knowledge adoption. Information Systems Research, 14(1), 47-65.

[3] Lee, Y. K., Kenneth, A., \& Larsen, K. R. T. (2003). The technology acceptance model: Past, present, \& future. Communications of the Association for Information Systems, 12, 751-780.

[4] Sejin, H., \& Leslie, S. (2009). Consumer e-shopping acceptance: Antecedents in a technology acceptance model. Journal of Business Research, 62(5), 565-571.

[5] Wang, X., et al. (2012). Social media peer communication \& impacts on purchase intentions: A consumer socialization framework. Journal of Interactive Marketing, 26(4), 198-208.

[6] Dong, H. Z., Ya, P. C., \& Jian, J. L. (2016). Understanding the influence of C2C communication on purchase decision in online communities from a perspective of information adoption model. Telematics \& Informatics, 33(1), 8-16.

[7] Igbaria, M. (1993). User acceptance of microcomputer technology: An empirical test. International Journal of Management Science, 21(1), 73-90.

[8] Gefen, D., \& Keil, M. (1998). The impact of developer responsiveness on perceptions of usefulness \& ease of use: An extension of the technology acceptance model. The Data Base for Advances in Information Systems, 29(2), 35-49.

[9] Cheng, B. H., \& Bao, G. M. (2003). The empirical study of the determinants of online purchase intention. The Journal of Quantitative \& Technical Economics, 11, 150-153.

[10] Gefen, D., \& Straub, D. W. (2000). The relative importance of perceived ease of use in IS adoption: A study of e-commerce adoption. Journal of the Association for Information Systems, 1(1), 1-30.

[11] Gefen, D., Karahanna, E., \& Straub, D. W. (2003). Trust \& TAM in online shopping: An integrated model. MIS Quarterly, 27(1), 51-90.

[12] Ver, H., Hans, V., \& Tibert, C. (2003). Understanding online purchase intentions: Contributions from technology \& trust perspectives. European Journal of Information Systems, 12(1), 41-48.

[13] Yu, K. Z., \& Song, Z. (2005). Trust, TAM \& the online purchase behavior. The Theory \& Practice of Finance \& Economics, 9, 119-123.

[14] Zhu, J. W. (2005). Study of Factors Impacting on Consumers' Online Shopping. Master thesis, Xian Jiaotong University of China.

[15] Liu, M. L., \& Li, Z. C. (2006). The empirical study of the influential factors of consumer behavior in the e-commerce setting. The Internet Economic \& E-commerce, 18(7), 32-37.

[16] Zhu, L. (2006). A Study on Consumer Behavior Intention on Online Shopping. Master thesis, Guangxi University of China.

[17] Liu, L. J. (2007). A Study of Consumer Online Purchase Intention, Based on Technology Acceptance Model 
\& Perceived Risk. Master thesis, Central South University of China.

[18] Ye, L. R., \& Zhang, H.-H. (2014). Sales promotion \& purchasing intention: Applying the technology acceptance model in consumer-to-consumer marketplaces. International Journal of Business, Humanities \& Technology, 4(3), 1-5.

[19] Leo, R. V. (2004). Predicting consumer intentions to use on-line shopping: The case for an augmented technology acceptance model. Information \& Management, 41(6), 747-762.

[20] Jie, L. (2008). A Study on the Influential Factors of Consumer Online Purchase Intention, Based on TAM \& IDT. Master Thesis, University of Electronic Science \& Technology of China.

[21] Shang, R.-A., et al. (2005). Extrinsic versus intrinsic motivations for consumers to shop online. Information \& Management, 42, 401-413.

[22] Said, S. (2011). Modeling the electronic transactions acceptance using an extended technology acceptance model. Applied Computing \& Informatics, 9(1), 47-77.

[23] Çelik, H. E., \& Veysel, Y. (2011). Extending the technology acceptance model for adoption of e-shopping by consumers in turkey. Journal of Electronic Commerce Research, 12(2), 152-164.

[24] Mao, Y., et al. (2014). Consumer purchase intention research based on social media marketing. International Journal of Business \& Social Science, 5(10), 92-97.

[25] Yi, J. L., et al. (2016). Factors influencing online shopping behavior: The mediating role of purchase intention. Procedia Economics \& Finance, 35, 401-410.

[26] Petty, R., \& Cacioppo, J. (1983). Communication \& Persuasion: Central \& Peripheral Routes to Attitude Change. New York.Springer-Verlag.

[27] Harrison, D., \& Charles, J. K. (2007). Factors \& effects of information credibility. Proceedings of the ninth International Conference on Electronic Commerce (pp. 423-432).

[28] Christy, M. K. C., et al. (2008). The impact of electronic word-of-mouth: The adoption of online opinions in online customer communities. Internet Research, 18(3), 229-247.

[29] Jin, X. L., Cheung, C. M., Lee, M. K., \& Chen, H. P. (2009). How to keep members using the information in a computer-supported social network. Computers in Human Behavior, 25(5), 1172-1181.

[30] Chen, C. W., et al. (2011). The study of eWOM adoption model. Marketing Review, 2(8), 175-198.

[31] Ismail, E., \& Chris, E. (2016). The influence of eWOM in social media on consumers' purchase intentions: An extended approach to information adoption. Computers in Human Behavior, 61, 47-55.

[32] Ika, A., et al. (2014). The impact of cognitive trust \& e-WOM on purchase intention in C2C e-commerce site. Journal of Computer Science, 10(12), 2518-2524.

[33] Dedy, D. G., \& Huarng, K.-H. (2015). Viral effects of social network \& media on consumers' purchase intention. Journal of Business Research, 68(11), 2237-2241.

[34] Tan, Y.-H., \& Thoen, W. (2001). Toward a generic model of trust for electronic commerce. International Journal of Electronic Markets, 5(2), 61-74.

[35] Dan, J. K., Donald, L. F., \& Raoc, H. R. (2008). A trust-based consumer decision-making model in electronic commerce: The role of trust, perceived risk, \& their antecedents. Decision Support Systems, 44(2), 544-564.

[36] Lichtenthal, J. D., Wilson, D. T., \& Long, M. M. (1997). Scientific contributions to the field from the journal of business-to-business marketing. Journal of Business Research, 38(3), 211-234.

[37] Icek, A. (1991). The theory of planned behavior. Organizational Behavior \& Human Decision Processes, $50(2), 179-211$.

[38] Donnavieve, S., Satya, M., \& Sivakumar, K. (2005). Online peer \& editorial recommendations, trust, \& choice in virtual markets. Journal of Interactive Marketing, 19(3), 15-37.

[39] Brown, J. J., \& Reingen, P. H. (1987). Social ties \& word-of-mouth referral behavior. Journal of Consumer 
Research, 14(3), 350-362.

[40] Tsai, W. P., \& Sumantra, G. (1998). Social capital \& value creation: The role of intrafirm networks. The Academy of Management Journal, 41(4), 464-476.

[41] Bansal, H. S., \& Voyer, P. A. (2000). Word of mouth process within a service purchase decision context. Journal of Service Research, 3(2), 166-177.

[42] Daniel, Z. L., \& Rob, C. (2004). The strength of weak ties you can trust: The mediating role of trust in effective knowledge transfer. Management Science, 50(11), 1477-1490.

[43] Ajzen, I., \& Fishbein, M. (1975). Belief, Attitude, Intention \& Behavior: An Introduction to Theory \& Research. Addslon-Wesley, Reading MA.

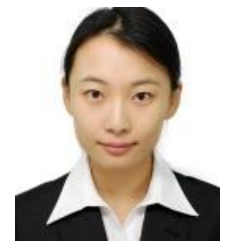

Yu Wang was born in Shandong province in China, on 28th September 1989. Yu Wang graduated from the Department of Science in Beijing Forestry University in China in 2008 and finished the master course in the Department of Economic and Management in Tohoku University in Japan in 2012. Now Yu Wang is taking the doctor course in Tohoku University and major in management.

She translated four books from English into Chinese, which include: 1) The Emotional Healing Strategy: A recovery guide for any setback, disappointment or loss (Beijing, China: China Changan Press, 2012); 2) Parenting Without Stress: How to Raise Responsible Kids While Keeping a Life of Your Own (Beijing, China: China Dizhen Press, 2012); 3) Inside Steve's Brain (Beijing, China: China Dizhen Press, 2013); 4) The Attachment Connection: Parenting a Secure \& Confident Child Using the Science of Attachment Theory (Beijing, China: China Dizhen Press, 2013). She is now interested in the influence of opinion leader towards the consumers' purchase decision in the virtual communities of consumption. 